\title{
Driving patterns in older adults with glaucoma
}

\author{
Suzanne W van Landingham, Chad Hochberg, Robert W Massof, Emilie Chan, David S Friedman \\ and Pradeep Y Ramulu
}

\begin{abstract}
Background: The ability to drive is important for ensuring quality of life for many older adults. Glaucoma is prevalent in this age group and may affect driving. The purpose of this study is to determine if glaucoma and glaucomatous visual field (VF) loss are associated with driving cessation, limitations, and deference to another driver in older adults.
\end{abstract}

Methods: Cross-sectional study. Eighty-one glaucoma subjects and 58 glaucoma suspect controls between age 60 and 80 reported if they had ceased driving, limited their driving in various ways, or preferred another to drive.

Results: Twenty-three percent of glaucoma subjects and $6.9 \%$ of suspects had ceased driving $(p=0.01)$. Glaucoma subjects also had more driving limitations than suspects (2.0 vs. 1.1, $p=0.007$ ). In multivariable models, driving cessation was more likely for glaucoma subjects as compared to suspects $(\mathrm{OR}=4.0 ; 95 \% \mathrm{Cl}=1.1-14.7 ; \mathrm{p}=0.03)$. The odds of driving cessation doubled with each 5 decibel $(\mathrm{dB})$ decrement in the better-eye VF mean deviation (MD) $(\mathrm{OR}=2.0 ; 95 \% \mathrm{Cl}=1.4-2.9 ; \mathrm{p}<0.001)$. Glaucoma subjects were also more likely than suspects to report a greater number of driving limitations $(\mathrm{OR}=4.7 ; 95 \% \mathrm{Cl}=1.3-16.8 ; \mathrm{p}=0.02)$. The likelihood of reporting more limitations increased with the VF loss severity ( $O R=1.6$ per $5 \mathrm{~dB}$ decrement in the better-eye VF MD; $95 \% \mathrm{Cl}=1.1-2.4 ; \mathrm{p}=0.02$ ). Neither glaucoma nor VF MD was associated with other driver preference ( $p>0.1$ for both).

Conclusions: Glaucoma and glaucomatous VF loss are associated with greater likelihood of driving cessation and greater limitation of driving in the elderly. Further prospective study is merited to assess when and why people with glaucoma change their driving habits, and to determine if their observed self-regulation of driving is adequate to ensure safety.

\section{Background}

Over 60 million people worldwide are affected by glaucoma, a number that will increase substantially as the population ages [1]. Glaucoma prevalence is highest among the elderly, and elderly individuals with glaucoma are more likely to be visually disabled because of more advanced visual field (VF) loss and other age-related factors [2].

Driving is highly valued by older adults because it is often required for independence [3]. Furthermore, driving cessation is associated with incident depression and increased risk of entry into a long term care facility, even after controlling for demographic and health variables [3]. Indeed, the ability to travel outside the home is consistently ranked as one of the two most important visual functions by people with glaucoma $[4,5]$.
Drivers with glaucoma perceive greater difficulty with driving, and perceived difficulty increases with severity of VF loss [6]. Drivers with glaucoma have also been shown to make more driving errors during driving simulator and on-road evaluation of driving $[7,8]$. Some studies have also shown that VF loss severity is associated with increased motor vehicle accidents (MVAs) [9-11], though others have shown that a glaucoma diagnosis is not associated with more accidents [12,13].

One explanation for why glaucoma does not consistently increase accident risk in all studied populations is that individuals with more advanced disease may limit or stop driving $[12,14-16]$. Here, we examine how driving patterns (driving limitation, driving cessation, and other driver preference) differ in glaucoma patients across a range of VF loss severities.

\footnotetext{
* Correspondence: pramulu1@jhmi.edu

Wilmer Eye Institute, Johns Hopkins University, 600 N. Wolfe St., Baltimore, MD 21287, USA
}

\section{Biomed Central}

(c) 2013 van Landingham et al.; licensee BioMed Central Ltd. This is an Open Access article distributed under the terms of the Creative Commons Attribution License (http://creativecommons.org/licenses/by/2.0), which permits unrestricted use, distribution, and reproduction in any medium, provided the original work is properly cited. 


\section{Methods}

\section{Subjects}

This is a cross-sectional study of subjects recruited from the Glaucoma Clinic at the Wilmer Eye Institute of Johns Hopkins Hospital between July 2009 and June 2011. Subjects' charts were prescreened for eligibility. Eligible subjects had to be between the ages of 60-80 years and be former or current drivers.

Glaucoma subjects were restricted to those having a physician diagnosis of primary open angle glaucoma, primary angle closure glaucoma, pseudoexfoliation glaucoma, or pigment dispersion glaucoma. Most glaucoma subjects had 24-2 VF tests within the 15 months prior to enrollment from a Humphrey Field Analyzer II (Carl Zeiss Meditec, Dublin CA) using the Standard Swedish Interactive Testing Algorithm showing a VF MD worse than $-3 \mathrm{~dB}$ and a borderline or abnormal GHT result in both eyes. Individuals whose most recent fields were 10-2 VFs were also included, in which case their bettereye MD was defined using the last recorded 24-2 VFs.

Glaucoma suspect controls were recruited from patients with a chart diagnosis of ocular hypertension or glaucoma suspect. They were required to have a presenting visual acuity of $20 / 40$ or better in both eyes and 24-2 VF tests within the 15 months prior to enrollment indicating a mean deviation (MD) better than -5 decibels $(\mathrm{dB})$ in both eyes and normal or borderline glaucoma hemifield test (GHT) results.

This study was approved by the Johns Hopkins Institutional Review Board. All subjects gave informed consent.

\section{Evaluation of driving habits}

Driving habits were evaluated with an intervieweradministered questionnaire taken from the Salisbury Eye Evaluation Driving Study (SEEDS), which added additional questions to other questionnaires previously used in the Salisbury Eye Evaluation [17,18]. Subjects were asked, "Have you driven a car in the past three months?" to assess driving cessation. In those who were currently driving, 9 different driving limitations were assessed: (1) not driving outside of the mid-Atlantic region (defined for this Baltimore-based study as Maryland, Virginia, Delaware, the District of Columbia and Pennsylvania), (2) not driving more than one hour away from home, (3) not driving to neighboring towns or areas, (4) not driving beyond the neighborhood, (5) not driving in the rain, (6) not driving at night, (7) not driving in unfamiliar areas, (8) driving less than twice per week, and (9) driving less than 5,000 miles (the standard for restricted driving in Maryland). Each of these limitations was assessed for the past year except for driving at night and driving in unfamiliar areas, which were assessed for the past three months. The questionnaire asked whether a person had performed a particular driving activity at all during the appointed time frame, not if they avoided that particular driving activity or if they were legally prohibited from doing it.

Driver preference was assessed by asking subjects, "in a typical week when you travel in a car, how often are you the driver?" Subjects who reported that they were the driver $50 \%$ or less of the time they rode in a car were considered to prefer another driver.

\section{Measurement of vision and covariates}

Monocular visual acuities were measured using the Early Treatment Diabetic Retinopathy Study (ETDRS) chart transilluminated at 130 candelas $/ \mathrm{m}^{2}$ and converted to the logarithm of the minimum angle of resolution (logMAR) for use in statistical analysis [19]. VF MD results were extracted from the chart. VF and visual acuity of the better-seeing eye were used for further analysis. Binocular contrast sensitivity (CS) was measured using the Pelli-Robson chart at 1 meter with subjects wearing their usual correction and converted into log units for analysis [20].

Both eyes were examined after pupillary dilation for significant lenticular changes defined as nuclear sclerosis greater than grade 2 on the Wilmer Cataract Grading system [21], blocked retroillumination in $\geq 4 / 16$ of the pupil due to cortical changes, any opacity in the central $3 \mathrm{~mm}$ of the posterior capsule, or, in pseudophakic eyes, posterior capsular opacification (PCO) demonstrating changes more severe than the "mild" image in Findl et al [22].

Demographic information collected included age, gender, race, employment status, years of education completed, living situation (if the subject lives with any other adults), and marital status, all by self-report. Cognitive ability was assessed using the Mini Mental Status Exam (MMSE) for the Visually Impaired [23]. Depressive symptoms were detected using the Geriatric Depression Scale Short Form, with subjects demonstrating 6 or more positive responses considered to have depressive symptoms [24]. Medical comorbidities were assessed using a standardized structured medical history questionnaire and summarized as the number of comorbid conditions present [25]. We inquired about arthritis, broken or fractured hip, back problems, heart attack/ myocardial infarction, angina/chest pain, congestive heart failure, peripheral vascular disease, hypertension, diabetes, emphysema, asthma, stroke, Parkinson's, cancer (other than skin cancer), and vertigo/Meniere's.

\section{Statistical analysis}

Group differences for continuous variables were evaluated using the Wilcoxon rank-sum test. Chi-square analysis was used to assess differences in categorical variables (Stata 11.2, College Station, TX). 
Binary outcomes, including driving cessation, driver preference, and the presence of each specific driving limitation were assessed using univariate and multivariable logistic regression models. The overall number of limitations was assessed in univariate and multivariable ordinal logistic regression models after trifurcating the number of driving limitations into three categories $(<3,3-4$, and $>4$ limitations). These categories were chosen to fulfill the proportional odds assumption, which was verified using the Brant test.

\section{Results}

One hundred and thirty-nine current or previous drivers participated in this study, including 81 with glaucoma and 58 suspects. Suspects and glaucoma subjects were similar with regards to most health and demographic characteristics (Table 1). Glaucoma subjects had worse visual acuity (median $\operatorname{logMAR}$ of 0.15 versus 0.08 in the better-seeing eye), worse VF results (better-eye median VF MD of -7.9 versus $+0.2 \mathrm{~dB}$ ), worse contrast sensitivity (1.6 versus $1.9 \log$ units), and were more likely to be non-white when compared to suspects (Table 1).

In unadjusted analyses, more glaucoma subjects than suspects had ceased driving $(22.5 \%$ vs. $6.9 \%, \mathrm{p}=0.02)$. Glaucoma subjects also had a greater mean number of driving limitations (2.0 vs. $1.1, \mathrm{p}=0.004)$ and were more likely to have ceased driving at night compared to suspects $(27.4 \%$ vs. $7.4 \%, \mathrm{p}=0.005)$ (Table 2). Differences between the two groups in the prevalence of all other limitations were not statistically significant, although a higher proportion of subjects with glaucoma endorsed each limitation.

When adjusting for age, race, gender, unemployment, cognition, comorbidities, and depressive symptoms, subjects with glaucoma were four times more likely than glaucoma suspect controls to have ceased driving (odds ratio $[\mathrm{OR}]=4.0 ; 95 \% \mathrm{CI}=1.1-14.7 ; \mathrm{p}=0.03$ ) (Table 3). Among glaucoma subjects, driving cessation became more likely with more severe VF loss $(\mathrm{OR}=2.0$ for each $5 \mathrm{~dB}$ decrement in the better-eye $\mathrm{MD} ; 95 \% \mathrm{CI}=1.4-2.9$; $\mathrm{p}<0.001$ ) (Figure 1). Glaucoma subjects were also likely to report more driving limitations than glaucoma suspect controls $(\mathrm{OR}=4.7 ; 95 \% \mathrm{CI}=1.3-16.8 ; \mathrm{p}=0.02)$. The likelihood of reporting more limitations increased with the severity of VF loss $(\mathrm{OR}=1.6$ for each $5 \mathrm{~dB}$ decrement in the better-eye MD; $95 \% \mathrm{CI}=1.1-2.4 ; \mathrm{p}=0.02$ ) (Figure 2). Significant non-visual factors associated with driving habits included a higher risk of driving cessation in subjects with depressive symptoms $(\mathrm{OR}=16.5$; 95\% $\mathrm{CI}=2.2-123.7 ; \mathrm{p}=0.01)$ and a greater number of driving limitations in female subjects $(\mathrm{OR}=8.3 ; 95 \% \mathrm{CI}=2.0$ 35.2; $\mathrm{p}=0.004)$.

Additional multivariable regression models adjusting for the same characteristics described above compared

Table 1 Characteristics of study participants by glaucoma status

\begin{tabular}{|c|c|c|}
\hline & Glaucoma suspect controls $(n=58)$ & Glaucoma $(n=81)$ \\
\hline \multicolumn{3}{|l|}{ Vision } \\
\hline Better eye visual field, MD (dB) & $0.2(-0.7,0.9)$ & $-7.9^{*}(-15.4,-4.8)$ \\
\hline Binocular CS, log units & $1.9(1.8,2.0)$ & $1.6^{*}(1.4,1.8)$ \\
\hline Better eye acuity, logMAR & $0.08(0.00,0.16)$ & $0.15^{*}(0.08,0.32)$ \\
\hline Sig. cataract/PCO, either eye (\%) & 22.2 & 35.8 \\
\hline Sig. cataract/PCO, both eyes (\%) & 9.3 & 11.1 \\
\hline \multicolumn{3}{|l|}{ Demographics } \\
\hline Age (years) & $69.8(65.6,73.0)$ & $70.3(66.4,74.5)$ \\
\hline White race (\%) & 77.6 & $62.5^{*}$ \\
\hline Female gender (\%) & 60.3 & 51.3 \\
\hline Education (years) & $17(14,17)$ & $16(14,17)$ \\
\hline Unemployment (\%) & 60.3 & 57.5 \\
\hline Lives with others (\%) & 81.0 & 81.2 \\
\hline Married (\%) & 67.2 & 62.5 \\
\hline \multicolumn{3}{|l|}{ Health/cognition } \\
\hline MMSE-VI score & $21(20,22)$ & $21(20,22)$ \\
\hline Comorbid illnesses (\#) & $2(1,3)$ & $2(1,3)$ \\
\hline Depressive symptoms (\%) & 5.2 & 5.9 \\
\hline
\end{tabular}

Continuous variables reported as median (inter-quartile range).

${ }^{*} P<0.05$ as compared to glaucoma suspect controls.

LogMAR = logarithm of the minimum angle of resolution; $M D=$ mean deviation; $\mathrm{dB}=$ decibels; $C S=$ contrast sensitivity; $P C O=P$ Posterior capsular opacification; MMSE VI = Mini-Mental Status. 
Table 2 Driving limitations in current drivers with and without glaucoma

\begin{tabular}{|c|c|c|c|}
\hline Driving limitation & Glaucoma suspects $\%(n=54)$ & Glaucoma\% $(n=62)$ & $P$ value \\
\hline Has not driven at night* & 7 & 27 & 0.005 \\
\hline Has not driven in the rain & 0 & 7 & 0.06 \\
\hline Has not driven in unfamiliar areas* & 19 & 31 & 0.13 \\
\hline Has not driven more than one hour away & 15 & 25 & 0.21 \\
\hline Has not driven beyond the neighborhood & 0 & 2 & 0.35 \\
\hline Has not driven to neighboring towns or areas & 2 & 7 & 0.23 \\
\hline Has not driven outside the region & 53 & 71 & 0.05 \\
\hline Drives $<2$ times per week & 2 & 5 & 0.38 \\
\hline Drove $<5,000$ miles per year & 15 & 24 & 0.21 \\
\hline
\end{tabular}

*These questions refer to the past three months. All other limitations refer to the past year.

All percentages rounded to integers.

the relative impact of different elements of vision (VF, visual acuity, contrast sensitivity, and presence of cataract) on driving cessation and limitations. In models that included both VF MD and visual acuity, the associations of VF loss with both driving cessation $(\mathrm{OR}=1.7 ; 95 \% \mathrm{CI}$ $=1.1-2.5 ; \mathrm{p}=0.008)$ and driving limitation $(\mathrm{OR}=1.6$; $95 \% \mathrm{CI}=1.0-2.4 ; \mathrm{p}=0.04)$ persisted, as did the association between visual acuity and driving cessation $(\mathrm{OR}=$ 1.3; $95 \% \mathrm{CI}=1.0-1.6 ; \mathrm{p}=0.03$ ). In models including both better-eye VF MD and contrast sensitivity, only the association between contrast sensitivity and driving cessation $(\mathrm{OR}=1.3 ; \quad 95 \% \quad \mathrm{CI} \quad 1.1-1.6 ; \quad \mathrm{p}=0.002)$ remained significant, though the two measures of vision loss were significantly correlated $(\mathrm{r}=0.75 ; \mathrm{p}<0.001)$. Finally, in models including both cataract/PCO and better-eye VF $\mathrm{MD}$, the associations between glaucoma severity and driving cessation $(\mathrm{OR}=2.0 ; 95 \% \mathrm{CI}=1.4-2.9 ; \mathrm{p}<0.001)$ and driving limitations were unchanged $(\mathrm{OR}=1.6 ; 95 \%$ $\mathrm{CI}=1.1-2.4 ; \mathrm{p}=0.02$ ).

Driver preference was not associated with glaucoma or VF loss severity, even when adjusting for age, race, gender, employment, living situation, marital status, and cognition (Table 3). Preferring another driver was dramatically more likely in females $(\mathrm{OR}=24.4 ; 95 \% \mathrm{CI}=$

Table 3 Effect of glaucoma and glaucoma severity on driving status, multivariable analysis

\begin{tabular}{|c|c|c|c|c|}
\hline Variable & Interval & $\begin{array}{c}\text { Not driving } \\
\text { Odds ratio }(95 \% \mathrm{Cl})\end{array}$ & $\begin{array}{c}\text { Increased limitations }^{\S} \\
\text { Odds ratio }(95 \% \mathrm{Cl})\end{array}$ & $\begin{array}{c}\text { Pref. another driver } \\
\text { Odds ratio }(95 \% \mathrm{Cl})\end{array}$ \\
\hline \multicolumn{5}{|l|}{ Vision } \\
\hline Glaucoma & Present & $4.0^{*}(1.1-14.7)$ & $4.7^{*}(1.3-16.8)$ & $1.7(0.54-5.3)$ \\
\hline Better eye visual field, MD & $5 \mathrm{~dB}$ worse & $2.0^{*}(1.4-2.9)$ & $1.6^{*}(1.1-2.4)$ & $1.3(0.88-2.0)$ \\
\hline Binocular contrast sensitivity & 1 letter worse ${ }^{+}$ & $1.3^{*}(1.2-1.4)$ & $1.2^{*}(1.1-1.3)$ & $1.1(0.92-1.2)$ \\
\hline Better eye acuity, logMAR & 1 line worse ${ }^{++}$ & $1.5^{*}(1.2-1.8)$ & $2.1 *(1.3-3.5)$ & $0.92(0.67-1.2)$ \\
\hline \multicolumn{5}{|l|}{ Demographics } \\
\hline Age & 5 yrs older & $1.2(0.69-2.0)$ & $1.7(0.96-3.1)$ & $1.2^{*}(1.0-1.3)$ \\
\hline Race & White & $0.6(0.20-1.8)$ & $1.0(0.31-3.5)$ & $1.2(0.34-4.0)$ \\
\hline Gender & Female & $1.3(0.45-3.7)$ & $8.3^{*}(2.0-35.2)$ & $24.4^{*}(5.0-11.8)$ \\
\hline Unemployment & Present & $0.7(0.23-2.2)$ & $3.4(0.88-13.0)$ & $3.0(0.86-10.8)$ \\
\hline Living situation & Lives with others & - & - & $48.4^{*}(1.9-1201)$ \\
\hline Marital Status & Married & - & - & $0.91(0.46-1.8)$ \\
\hline \multicolumn{5}{|l|}{ Health/cognition } \\
\hline MMSE VI score & 5 points lower & $4.1(0.85-19.5)$ & $0.22(0.02-2.6)$ & $19.7^{*}(1.7-227)$ \\
\hline Comorbidities & 1 illness & $1.0(0.72-1.4)$ & $1.20(0.84-1.7)$ & - \\
\hline Depressive Symptoms & Present & $16.5^{*}(2.2-123.7)$ & $0.43(0.03-5.7)$ & - \\
\hline
\end{tabular}

Odds ratios for vision variables were each derived from separate multivariable models including all non-visual covariates shown.

Odds ratios for non-vision variables were all derived from multivariable models including better-eye MD and all non-visual variables shown.

${ }^{5}$ Refers to current drivers only.

${ }^{+}$Corresponds to 0.05 log unit change.

${ }^{++}$Corresponds to 0.1 logMAR change.

* $P<0.05$ 


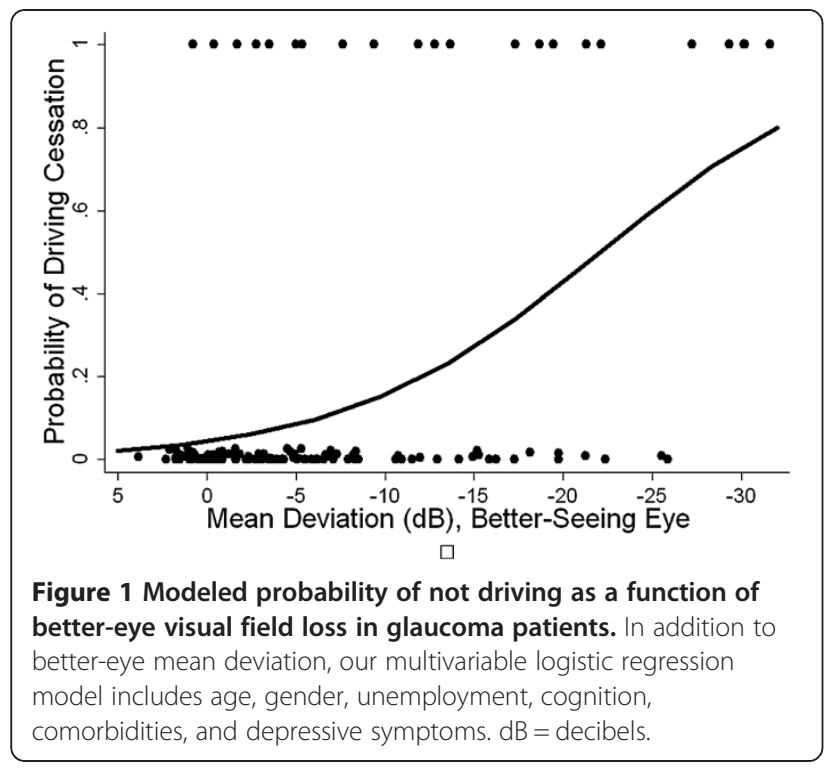

5.0-118; $\mathrm{p}<0.001)$, in those who live with another adult $(\mathrm{OR}=46.2 ; 95 \% \mathrm{CI}=1.9-1094 ; \mathrm{p}=0.02)$, and in those with lower cognitive ability $(\mathrm{OR}=19.8 ; 95 \% \mathrm{CI}=1.7-227$; $\mathrm{p}=0.02)$. No other characteristics predicted preferring another driver $(\mathrm{P}>0.05)$.

\section{Discussion and conclusions}

Individuals with glaucoma were significantly more likely than glaucoma suspects to have limited or stopped their driving in this clinic-based study. Driving cessation and driving limitations were also more common with more severe VF loss (Figures 1 and 2).

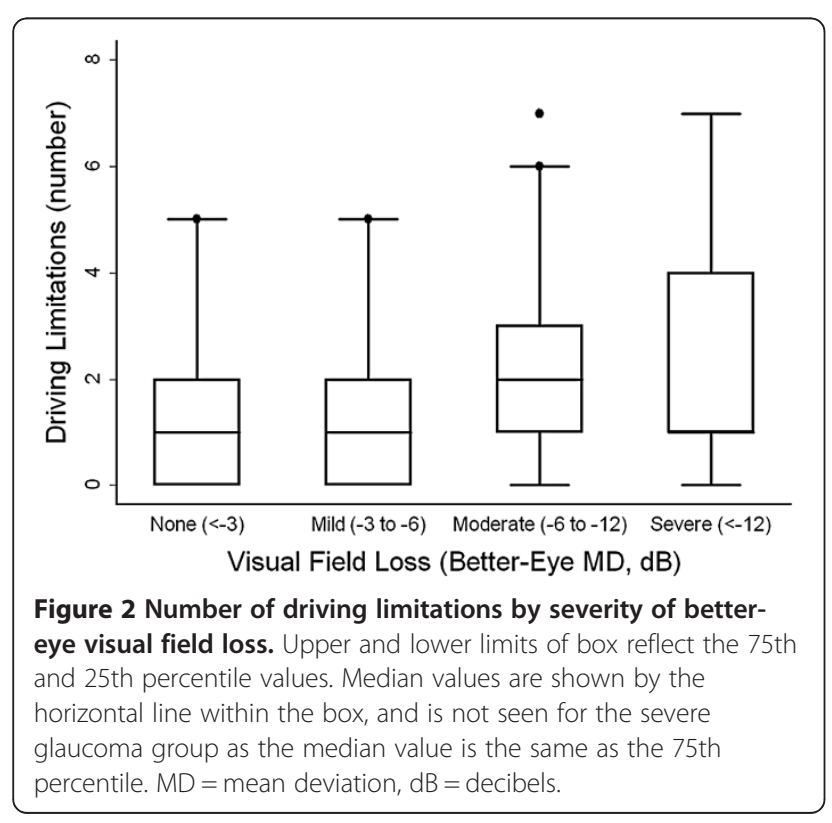

The presence of the association between glaucoma and driving cessation found in the current work corroborates previous studies. The Blue Mountain Eye Study reported a greater than 2-fold increased odds of driving cessation for subjects with glaucoma or impaired visual acuity after adjusting for age and gender [16], though subjects were not classified by disease severity. The Salisbury Eye Evaluation found an association between bilateral glaucoma and driving cessation in the elderly and a 2-fold greater risk of driving cessation with every $5 \mathrm{~dB}$ decrement in the better-eye VF [14]. The consistency of findings across studies supports the idea that driving cessation becomes more common with greater VF loss in numerous driving environments.

Previous studies have differed in their assessment of whether people with glaucoma are more likely to limit their driving. The Salisbury Eye Evaluation found no significant associations between glaucoma and driving limitations, but our study and two others did $[12,14,15]$. The discrepancies between different studies may be explained by demographic differences in the study populations. For example, our study population was younger (mean age 70) and our study location was urban while the Salisbury Eye Evaluation assessed an older (mean age 80), rural group. The current study is the first to demonstrate greater driving limitations with increasing disease severity.

Driving cessation is clearly an effective method for avoiding some of the risks associated with VF loss. However, the extent to which limitation of driving is a successful method for balancing safety and independence remains unknown. One possibility is that those who limit their driving due to VF loss succeed in reducing their risk of MVAs to a level similar to or even lower than other drivers. This hypothesis could partially explain why some previous studies found that having a glaucoma diagnosis may not increase older individuals' risk of MVAs [12,13]. However, a second possibility is that, despite limiting their driving, individuals with glaucomatous VF loss still drive poorly and/or unsafely. This is supported by studies showing that VF loss is a risk factor for MVAs [9-11]. Further study is needed to clarify the adequacy of these selfimposed driving limitations in keeping drivers safe.

Another adaptation that drivers with glaucoma may make is deferring to another driver. However, neither glaucoma nor the severity of VF loss predicted driver preference in the current study, which implies that glaucoma is not a factor influencing driver preference independent of other more significant factors such as gender and age. As such, the selection of a driver within a family may often be determined by traditional gender roles rather than by driving skill.

Our study also identified several other non-visual characteristics associated with driving habits. Depression 
was associated with driving cessation and may be both a risk factor for and a consequence of driving cessation [14]. Females were more likely to limit their driving $[14,16,17]$. Females, individuals living with another driver, older individuals, and individuals with impaired cognition were also more likely to prefer another driver. These findings highlight the need to account for nonvisual factors when making recommendations regarding driving.

The present study also sought to determine which measure of vision best predicts driving limitations in individuals with glaucoma. Contrast sensitivity appeared to best predict driving cessation, so when information on contrast sensitivity is available, it may be useful in guiding conversations about driving. Contrast sensitivity is highly correlated with better-eye VF MD in glaucoma patients, however so the two measurements are essentially interchangeable for this purpose.

The use of self-report to assess driving habits in this study is a potential source of bias, as subjects may feel motivated to conceal unsafe driving behaviors. It can provide valuable information about subjects' perceived limitations, however, which may have a strong impact on quality of life. Other studies have used simulators and direct on-road evaluation to assess the impact of glaucoma on driving [7,26-28]. These methodologies have the advantage of allowing direct observation of driving performance, thereby limiting self-report bias, but offer a limited period of observation. Also, the driver is not in their own car or typical driving environment, which may impact their driving performance. The Salisbury Eye Evaluation Driving Study used driver monitoring systems installed in subjects' cars to study the impact of vision on driving in a population-based cohort of older adults [8]. While that study was not powered to detect the impact of glaucoma on driving, it represents a promising strategy for studying the impact of vision loss on driving in the person's native environment.

A limitation of our study was that driving changes were not assessed prospectively, so we cannot draw conclusions about the stage of disease at which driving limitations and driving cessation first occurred. Also, our control population was comprised of glaucoma suspects rather than true 'normals' not under ophthalmologic care. We felt that this was the best control group for our study as it would balance any potential bias caused by recruitment from a referral center. Additionally, normals recruited from spouses or volunteers are likely to exclude those with mobility limitations, thus overestimating findings. This suspect group reported minimal driving limitations (6.9\% driving cessation and an average of 1.1 driving limitations vs. $22.5 \%$ cessation and 1.9 limitations for the glaucoma group), suggesting that these glaucoma suspects were not altering their driving habits due to knowledge of their disease risk. Finally, we utilized better-eye VF loss as a metric of glaucoma severity instead of measures aimed at integrating right and left eye VF results to simulate binocular VF loss. Previous work has shown that better-eye MD is typically slightly worse than integrated VF MD, and differs from integrated VF MD by $2 \mathrm{~dB}$ or more in roughly one in 4 patients $[29,30]$. Thus, it is possible that results would have been different if integrated VF MD was used as a metric of VF loss. However, binocular VF loss is not easily calculated in clinic and did not predict subjective or objective measures of disability better than better-eye VF loss in one study [31]. Better-eye MD has been shown to predict legal fitness to drive in the United Kingdom just as well as models which incorporated VF MDs from both eyes [32], though further work will be necessary to determine if better-eye and integrated VF metrics predict actual disability to a similar extent.

The choice to cease or limit driving is likely guided by both fitness to drive and other factors. Regulating fitness to drive is best achieved by combining information regarding real-world patient choices and observation of driving in simulated or real-world situations, and relating them to measures of VF loss [33]. The fact that patients with glaucoma are more likely to limit their driving is encouraging and may indicate that glaucoma patients as a whole are self-regulating in such a way as to keep themselves (and others) safe on the road. Further prospective study is merited to assess when and why people with glaucoma change their driving habits, and perhaps to assess MVAs per mile driven in this group. Because of the potential for driving cessation and limitation to negatively affect individuals' quality of life, it will be important to balance safety and independence for drivers with visual impairment due to glaucoma.

\section{Competing interests}

The authors declare that they have no competing interests relating to this work. This research was supported in part by the Dennis W. Jahnigen Memorial Award, NIH Grant EY018595, the Research to Prevent Blindness Robert and Helen Schaub Special Scholar Award, the Intramural Research Program of the NIH (National Institute on Aging), and the Doris Duke Charitable Research Foundation Clinical Research Fellowship. All funding organizations had no role in the design or conduct of this research.

\section{Authors' contributions}

SV participated in data collection, data analysis, and drafting of the manuscript. $\mathrm{CH}$ participated in data collection and data analysis. RM participated in data analysis. EC participated in study design and data collection. DF participated in study design. PR participated in study design, data analysis, and oversaw conduct of the study. All authors contributed to revising the manuscript for important intellectual content, read, and approved the final manuscript.

Received: 29 May 2012 Accepted: 22 January 2013

Published: 21 February 2013

\section{References}

1. Quigley HA, Broman AT: The number of people with glaucoma worldwide in 2010 and 2020. Br J Ophthalmol 2006, 90:262-267. 
2. Mukesh BN, McCarty CA, Rait JL, Taylor HR: Five-year incidence of openangle glaucoma: the visual impairment project. Ophthalmology 2002, 109:1047-1051.

3. Freeman EE, Gange SJ, Muñoz B, West SK: Driving status and risk of entry into long-term care in older adults. Am J Public Health 2006, 96:1254-1259.

4. Burr JM, Kilonzo M, Vale L, Ryan M: Developing a preference-based Glaucoma Utility Index using a discrete choice experiment. Optom Vis Sci 2007, 84:797-808.

5. Aspinall PA, Johnson ZK, Azuara-Blanco A, Montarzino A, Brice R, Vickers A: Evaluation of quality of life and priorities of patients with glaucoma. Invest Ophthalmol Vis Sci 2008, 49:1907-1915.

6. Freeman EE, Muñoz B, West SK, Jampel HD, Friedman DS: Glaucoma and quality of life: the Salisbury Eye Evaluation. Ophthalmology 2008, 115:233-238.

7. Coeckelbergh TRM, Brouwer WH, Cornelissen FW, Van Wolffelaar P, Kooijman AC: The effect of visual field defects on driving performance: a driving simulator study. Arch Ophthalmol 2002, 120:1509-1516.

8. Keay L, Jasti S, Munoz B, Turano KA, Munro CA, Duncan DD: Urban and rural differences in older drivers' failure to stop at stop signs. Accid Anal Prev 2009, 41:995-1000.

9. Tanabe S, Yuki K, Ozeki N, Shiba D, Abe T, Kouyama K, Tsubota K: The association between primary open-angle glaucoma and motor vehicle collisions. Invest Ophthalmol Vis Sci 2011, 52:4177-4181.

10. Rubin GS, Ng ESW, Bandeen-Roche K, Keyl PM, Freeman EE, West SK: A prospective, population-based study of the role of visual impairment in motor vehicle crashes among older drivers: the SEE study. Invest Ophthalmol Vis Sci 2007, 48:1483-1491.

11. McGwin G Jr, Xie A, Mays A, Joiner W, DeCarlo DK, Hall TA, Owsley C: Visual field defects and the risk of motor vehicle collisions among patients with glaucoma. Invest Ophthalmol Vis Sci 2005, 46:4437-4441.

12. McGwin G Jr, Mays A, Joiner W, Decarlo DK, McNeal S, Owsley C: Is glaucoma associated with motor vehicle collision involvement and driving avoidance? Invest Ophthalmol Vis Sci 2004, 45:3934-3939.

13. Hu PS, Trumble DA, Foley DJ, Eberhard JW, Wallace RB: Crash risks of older drivers: a panel data analysis. Accid Anal Prev 1998, 30:569-581.

14. Ramulu PY, West SK, Munoz B, Jampel HD, Friedman DS: Driving cessation and driving limitation in glaucoma: the Salisbury Eye Evaluation Project. Ophthalmology 2009, 116:1846-1853.

15. Adler G, Bauer MJ, Rottunda S, Kuskowski M: Driving habits and patterns in older men with glaucoma. Soc Work Health Care 2005, 40:75-87.

16. Gilhotra JS, Mitchell P, Ivers R, Cumming RG: Impaired vision and other factors associated with driving cessation in the elderly: the Blue Mountains Eye Study. Clin Experiment Ophthalmol 2001, 29:104-107.

17. Freeman EE, Muñoz B, Turano KA, West SK: Measures of visual function and their association with driving modification in older adults. Invest Ophthalmol Vis Sci 2006, 47:514-520.

18. Turano KA, Munoz B, Hassan SE, Duncan DD, Gower EW, Roche KB, Keay L, Munro CA, West SK: Poor sense of direction is associated with constricted driving space in older drivers. J Gerontol B Psychol Sci Soc Sci 2009, 64:348-55.

19. Bailey IL, Bullimore MA, Raasch TW, Taylor HR: Clinical grading and the effects of scaling. Invest Ophthalmol Vis Sci 1991, 32:422-432.

20. Elliott DB, Sanderson K, Conkey A: The reliability of the Pelli-Robson contrast sensitivity chart. Ophthalmic Physiol Opt 1990, 10:21-24.

21. West SK, Munoz B, Wang F, Taylor H: Measuring progression of lens opacities for longitudinal studies. Curr Eye Res 1993, 12:123-132.

22. Findl O, Buehl W, Menapace R, Georgopoulos M, Rainer G, Siegl H, Kaider A, Pinz A: Comparison of 4 methods for quantifying posterior capsule opacification. J Cataract Refract Surg 2003, 29:106-111.

23. Busse A, Sonntag A, Bischkopf J, Matschinger $H$, Angermeyer MC: Adaptation of dementia screening for vision-impaired older persons: administration of the Mini-Mental State Examination (MMSE). J Clin Epidemiol 2002, 55:909-915.

24. Montorio I, Izal M: The Geriatric Depression Scale: a review of its development and utility. Int Psychogeriatr 1996, 8:103-112.

25. Turano KA, Broman AT, Bandeen-Roche K, Munoz B, Rubin GS, West S: Association of visual field loss and mobility performance in older adults: Salisbury Eye Evaluation Study. Optom Vis Sci 2004, 81:298-307.
26. Haymes SA, LeBlanc RP, Nicolela MT, Chiasson LA, Chauhan BC: Glaucoma and on-road driving performance. Invest Ophthalmol Vis Sci 2008, 49:3035-3041

27. Crabb DP, Smith ND, Rauscher FG, Chisholm CM, Barbur JL, Edgar DF, Garway-Heath DF: Exploring eye movements in patients with glaucoma when viewing a driving scene. PLoS One 2010, 5:e9710.

28. Medeiros FA, Weinreb RN, R Boer E, Rosen PN: Driving Simulation as a Performance-based Test of Visual Impairment in Glaucoma. J Glaucoma 2011, 21:221-227.

29. Nelson-Quigg JM, Cello K, Johnson CA: Predicting binocular visual field sensitivity from monocular visual field results. Invest Ophthalmol Vis Sc 2000, 41:2212-2221.

30. Asaoka R, Crabb DP, Yamashita T, Russell RA, Wang YX, Garway-Heath DF: Patients have two eyes!: binocular versus better eye visual field indices. Invest Ophthal Vis Sci 2011, 52:7007-7011.

31. Kulkarni KM, Mayer JR, Lorenzana LL, Myers JS, Spaeth GL: Visual field staging systems in glaucoma and the activities of daily living. Am J Ophthalmol 2012, 154:445-451.

32. Saunders LJ, Russel RA, Crabb DP: Practical landmarks for visual field disability in glaucoma. Br J Ophthalmol 2012, 96:1185-1189.

33. Owen VM, Crabb DP, White ET, Viswanathan AC, Garway-Heath DF, Hitchings RA: Glaucoma and fitness to drive: using binocular visual fields to predict a milestone to blindness. Invest Ophthalmol Vis Sci 2008, 49:2449-2455.

doi:10.1186/1471-2415-13-4

Cite this article as: van Landingham et al:: Driving patterns in older adults with glaucoma. BMC Ophthalmology 2013 13:4.

\section{Submit your next manuscript to BioMed Central and take full advantage of:}

- Convenient online submission

- Thorough peer review

- No space constraints or color figure charges

- Immediate publication on acceptance

- Inclusion in PubMed, CAS, Scopus and Google Scholar

- Research which is freely available for redistribution 